\title{
A NEW METHOD FOR DETERMINING THE SPECIFIC HEATS OF LIQUIDS.
}

\author{
BY E. J. HARTUNG, B.Sc.
}

\section{(A Paper read before the Faraday Society on Tuesday, May II, I915, Sir Robert Hadfield, F.R.S., President, in the Chair.)}

In the course of a research on certain thermal properties of binary liquid mixtures it was found necessary to measure the specific heats of a large number of liquids. It was therefore very desirable to have a simple, rapid, and reasonably accurate method of measurement. The following paper contains an account of a new method for determining the specific heats of liquids, which has been found very suitable for the purpose named. It has the added advantage of requiring a relatively small quantity (6o c.c.) of the particular liquid for a determination. The method retains the simplicity of the old mixture method for measuring specific heats while greatly diminishing its serious errors.

The initial idea, from which the method was worked out, was supplied by Professor Orme Masson, who suggested that the liquid in question be cooled by the application of a known weight of dry ice sealed up with a roll of silver gauze in a thin glass buib. This suggestion was acted upon, and, after suitable apparatus had been constructed, good and consistent results were obtained. The method in brief consists in freezing the bulb containing the water in a suitable apparatus and then introducing the bulb into the liquid in the calorimeter and noting the fall in temperature.

\section{Description of Apparatus.}

The apparatus consists of three parts : $I$, the ice carrier ; 2 , the freezing apparatus : 3 , the calorimeter.

The Ice Carrier (Fig. I).-This consists of a small, cylindrical, thin glass sealed bulb, containing from $I$ to 3 c.c. of pure water and as large a roll of silver gauze as possible. The respective masses of the glass, the water, and the silver are accurately known. The bulb is furnished with a small glass hook, to which is attached a fine platinum wire suspension. The silver gauze ensures rapid melting of the ice in the bulb when this is introduced into the calorimeter, and also makes the bulb heavy enough to sink in dense liquids. Sufficient free space must be left in the bulb to allow for the expansion of the water when freezing. It is convenient to make several ice carriers of different sizes.

The great advantage of these ice carriers, when compared with the previously used hot metals, etc., in mixture methods, lies in their small size and great "cold" capacity. Thus, a bulb containing 3 grams of ice, when rising in temperature from $0^{\circ}$ to $20^{\circ}$, absorbs well over 300 calories.

The Freezing Apparatus (Fig. 2). - This consists of a glass tube $(4 \mathrm{~cm}$. 
diameter and $I_{5} \mathrm{~cm}$. long) containing about too c.c. of clean dry mercury (E). It is closed by a well-fitting rubber stopper (A), which is perforated in the centre by a hole wide enough to allow the largest ice carrier in use to slip easily through. A standard thermometer (B), graduated to tenths of a degree, is provided with a small rubber cork, which fits this hole closely and allows the thermometer to dip into the mercury. The ice carrier is held under the mercury by means of two glass rods $(C)$ passing through the stopper. The ends of these rods are so shaped that a partial rotation of one rod above the stopper releases the carrier. A small calcium chloride tube (D) passes through the stopper and enables a stream of dry air to be drawn through the apparatus.

The carrier is withdrawn from the tube through the central hole in the

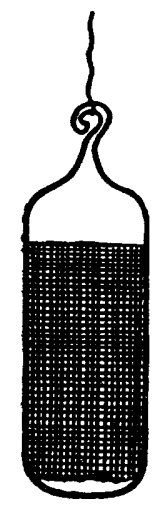

FIg. I.

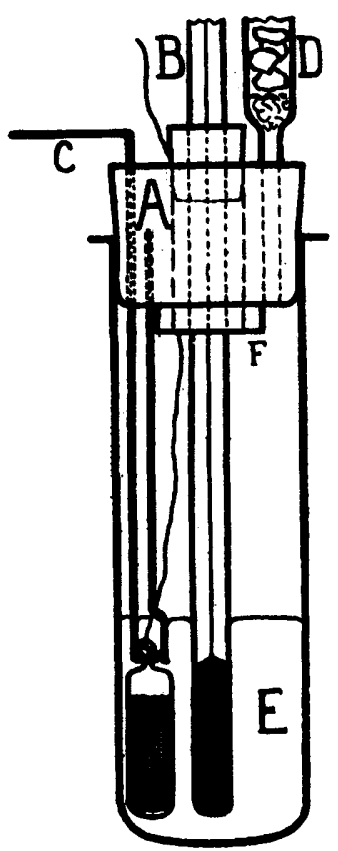

FIG. 2.

stopper after the removal of the thermometer. In order to ensure that no mercury adheres to the bulb, a thin perforated cardboard disc (F) is fixed just below the stopper. The perforation in this disc is lined with feather tips gummed to the cardboard and all pointing inwards. The carrier, in passing through the disc, is thoroughly wiped by the feathers and emerges from the tube quite clean.

The mercury tube fits into a wider glass tube which acts as an air jacket. The whole can be cooled in the usual bath of brine and ice.

The Calorimeter (Fig. 3).-This consists of a thin-walled cylindrical metal vessel (A) $(4 \mathrm{~cm}$. diameter and $8 \mathrm{~cm}$. depth) provided with a flanged edge and made preferably of platinum. The calorimeter used in these experiments was made of thin sheet copper, well silvered internally, and weighed 27 grams. The calorimeter is supported inside a silvered Dewar tube (B) (inner dimensions $5 \mathrm{~cm}$. diameter and $12 \mathrm{~cm}$. depth) by means of a rubber ring (C) (made 
from thick-walled tubing) encircling the calorimeter just below the flange. This ring fits tightly the inner jacket of the Dewar tube and rests securely on a ring of cardboard (D) gummed round the inside of the tube. The mouth of the tube is closed by a $5 \mathrm{~cm}$. rubber stopper $(E)$, which reaches to within a short distance from the top of the calorimeter. This leaves only a small space above the calorimeter in which the contained liquid can vaporize. The under surface of the stopper is protected from vapours by several layers of tinfoil. Through the stopper passes a previously calibrated and standardized Beckmann thermometer and a thin glass stirring-rod $(\mathrm{H})$, the lower end of which is suitably shaped to receive the ice carrier used. The stirrer is lubricated through the stopper with a little vaseline or phosphoric acid. The carrier itself is introduced into the calorimeter through a hole in the stopper lined with a short piece of glass tubing and closed with a small well-fitting rubber

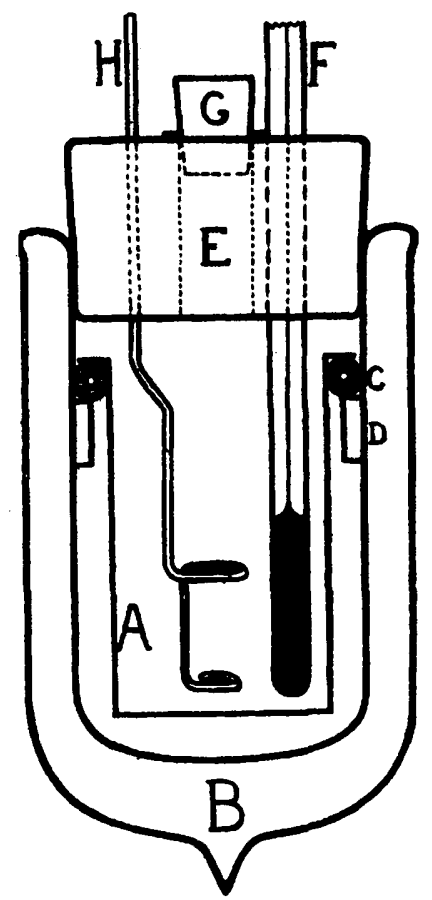

Fig. 3 .

stopper (G). The liquid to be experimented with is also introduced through this hole. The position of the stirring-rod can easily be arranged so that the carrier, on being introduced into the calorimeter, invariably slips into its place in the stirring-rod.

The Dewar tube is shielded from external radiations by being placed in a double-walled cylindrical wooden box packed with wool and provided with a separate perforated cover.

The Method of Experiment.

The liquid to be experimented with is put into a weight pipette and allowed to attain the room temperature. About 60 c.c. are then introduced 
into the calorimeter, and the latter is then closed and allowed to stand, with occasional stirring, until the temperature is constant, or at most changes very slowly. In the meantime, the selected ice carrier is secured under the mercury in the freezing-tube, and a current of dry air drawn through the apparatus for some minutes. This prevents any condensation of water inside the tube during the freezing. The standard thermometer is then inserted and the tube surrounded with a bath of brine and ice at about $-5^{\circ}$. Freezing of the water in the carrier takes place easily and rapidly. After a few minutes, the tube is removed, placed in its jacket, and surrounded with a second bath of brine and ice at approximately $-1^{\circ}$ until the temperature of the mercury is constant. This usually takes about ro minutes.

The temperatures in the calorimeter and the freezing apparatus are read. The thermometer is then removed from the latter, the bulb withdrawn by its suspension, and introduced into the stirring-rod in the calorimeter, which is then immediately closed again. These operations can be very rapidly performed, and little gain of heat by the bulb can result. The time is noted and hand stirring started, until in from two to three minutes the well-defined minimum temperature is reached. In order to correct for radiation errors, the rise in temperature for an equal interval is then noted. The water equivalent of the apparatus is previously determined, using distilled water as the contained liquid. All the data necessary for calculating the specific heat of the liquid are then known.

It has been found that the water equivalent of the apparatus varies to some extent with the time of experiment. This is specially noticeable if a thin glass calorimeter is substituted for the metal vessel, and is principally due to the poor conducting powers of glass. However, the variation is regular, and a graph is easily constructed which enables the water equivalent values, corresponding to the times of experiment, to be read off at once.

Occasionally a very small globule of mercury is introduced into the calorimeter with the ice carrier, but the amount is quite negligible. It is very convenient to perform the measurements in a room kept at approximately constant temperature. This obviates the continual standardising of the Beckmann thermometer with every change in the room temperature.

\section{Results Obtained.}

Several series of water equivalent determinations gave results not differing amongst themselves by more than $0_{4} 4$ per cent.

In order to test the apparatus, a series of specific heat measurements of mixtures of pure sulphuric acid and water were made, and the results were compared with the figures obtained for these mixtures by J. Thomsen.* For this purpose a thin glass calorimeter was used. The measurements were made between $17^{\circ}$ and $20^{\circ}$. The sulphuric acid used was a fresh sample of Schuchardt's pure $\mathrm{r} \cdot 84 \mathrm{sp}$. gr. acid. This acid was found to be free from oxides of nitrogen and to leave on evaporation only the slightest residue. Various mixtures were made up with distilled water in glass-stoppered flasks and the density $\left(\right.$ at $20^{\circ}$ ) and specific heat of each mixture measured. By reference to tables in Landolt's Physikalisch-chemische Tabellen, fifth edition, the compositions of the mixtures were calculated from the densities. The following table gives the actual results which were obtained, compared with the corresponding values taken from Thomsen's smoothed curve. The compositions of the solutions are given in the column headed " $N$," this denoting the number of molecules of sulphuric acid in one total molecule of solution.

- Thermochcmistry, J. Thomsen, Ramsay Physical Chemistry Series, p. I6r. 
TABLE I.

\begin{tabular}{c|c|c} 
N. & $\begin{array}{c}\text { Specific Heat } \\
\text { (Ice Method). }\end{array}$ & $\begin{array}{c}\text { Specific Heat } \\
\text { (Thomsen). }\end{array}$ \\
\hline 0.0155 & 0.947 & 0.949 \\
0.0236 & 0.909 & 0.904 \\
0.0451 & 0.842 & 0.835 \\
0.0566 & 0.807 & 0.802 \\
0.0786 & 0.751 & 0.745 \\
0.107 & 0.681 & 0.685 \\
0.142 & 0.615 & 0.619 \\
0.171 & 0.574 & 0.577 \\
\hline
\end{tabular}

Good agreement is shown between the two sets of results.

In the course of subsequent work, measurements were made on a series of pure liquids, but, owing to the very unsatisfactory nature of the available specific heat data for the majority of pure liquids, no proper comparisons can be made. The following table gives the results obtained between $17^{\circ}$ and $20^{\circ}$; the methods of purification of the liquids are held over for a subsequent paper.

TABLE II.

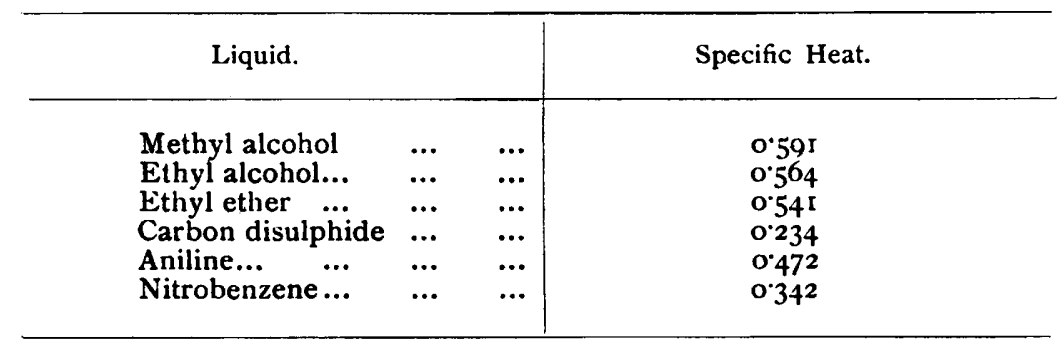

In conclusion, the method described is simple, rapid, and appears to bc reasonably accurate.

The author expresses his sincerest thanks to Professor Orme Masson and Mr. F. H. Campbell, M.Sc., for their kindly interest and advice.

Chemistry Department, Melbourne University, December, I9I. 